\title{
Toxicity of Herbal Pharmaceutical Wastewater to a Freshwater Crustacean Ceriodaphnia dubia
}

\author{
Shashikant Sitre $\cdot$ Sharda Dhadse $\cdot$ Shanta Satyanarayan
}

Received: 29 November 2007 / Accepted: 8 October 2008/Published online: 5 December 2008

(c) The Author(s) 2008. This article is published with open access at Springerlink.com

\begin{abstract}
The main objective of this study was to evaluate the acute toxicity of raw, neutralized and physicochemically treated and biologically treated effluent of herbal pharmaceutical industry. The acute toxicity test was determined using freshwater crustacean Ceriodaphnia $\mathrm{du}$ bia under laboratory conditions. $\mathrm{LC}_{50}$ values for raw, neutralized and physico-chemically treated effluent for 12 , 24,36 and $48 \mathrm{~h}$ ranged between $3.0-4.5 \%, 3.9-10.8 \%$ and $22-28 \%$ respectively. It is evident from the results that physicochemical treatment reduced the toxicity by around $25 \%$ while biological treatment reduced the toxicity completely. Results subjected to statistical evaluation depicted regression coefficient of more than 0.9 indicating good correlation between the mortality rate and effluent concentrations.
\end{abstract}

Keywords Acute toxicity - Ceriodaphnia .

Herbal pharmaceutical wastewater

Herbal pharmaceutical drugs have become more popular due to its safety, efficacy, cultural acceptability, low side effects and low cost compared to allopathic drugs. Herbal pharmaceuticals though less harmful generate huge volumes of wastewater during the manufacturing processes which includes washing of medicinal plants to remove dust particles, microbial contaminants etc. This wastewater is toxic to aquatic flora and fauna due to the presence of many plant alkaloids like nimbin and nimbidin which are present in neem plant (Azadirachta indica). Many parts of this tree

S. Sitre $\cdot$ S. Dhadse $(\bowtie) \cdot$ S. Satyanarayan

National Environmental Engineering Research Institute,

Nagpur, India

e-mail: sharda_dhadse@yahoo.com like the fruit, nut, leaves and bark are used in herbal medicine preparation. Apart from these alkaloids many chemicals like sugar, alcohol gelatin, lactose, organic solvents, clays, salts, special trace metals and edible oils are also used. Trace quantities of these also find their way into the wastewater. Apart from physical washing, wastewater is also generated from different processes like crushing, mixing, extraction, fermentation, distillation, decoction preparation and percolation based on the market requirement.

Routine physico-chemical parameters like $\mathrm{pH}$, alkalinity, dissolved oxygen, BOD, COD, TDS, SS are generally used for evaluation of effluent quality. However these parameters cannot be applied for toxicity evaluation and study the wastewaters effects on receiving water bodies, due to some specific effects. Generally best way to evaluate the effluent toxicity is to use biotoxicity test. Organic, inorganic and toxic constituents present in the effluents have direct impact on the aquatic life, particularly fish and hence have high ecological relevance. Predicted impacts of the wastewater on the flora and fauna vary widely due to the wide variations in the characteristics of the wastewater (Vanerkar et al. 2004). Characteristics of the wastewater depends on the types of medicine manufactured, raw materials used and also on the market demands. In general to evaluate the wastewater toxicity fish bioassays are carried out. In recent years, more attention is being given to acute toxicity evaluation of different industrial wastewaters due to the imposition of stringent laws on discharge standards.

In recent years apart, from fish bioassays more stress is being given to zooplankton assay. Zooplanktons are highly sensitive to pollution stress and many species of protozoa, rotifera and cladocera are known biological indicators of water quality of rivers and receiving water bodies like lakes and ponds (Katalin 1995). Among the chemical stress or 
toxicity responses of zooplankton the test for lethality has been measured most frequently since they are simplest to include in monitoring programmes and regulatory tests for compliance of discharge standards. The test may vary greatly in objectives, duration and desired toxicity ranges between $30 \mathrm{~s}$ to 4 days and are regarded as screening tests. While chronic toxicity tests with zooplankton varies from few days to several weeks. Different organisms such as fish algae, bacteria and other aquatic micro-organism may be used in biotoxicity test. Many zooplanktons viz. rotifers, cladocera, calanoid and copepoda have been widely used for toxicity evaluation in freshwater ecosystems (Tevlin and Burgis 1979). Based on the above literature an attempt has been made to evaluate the toxicity of herbal pharmaceutical wastewater on aquatic crustacean Ceriodaphnia dubia. This species is very common in freshwater, rivers and lakes of this region of the state of Maharashtra, India and considered as important fish food organisms in natural water bodies. Zooplankton toxicity testing to assess the adverse effects of industrial wastewaters is reported in literature. Sensitivity of Daphnia magna, Daphnia pulex, Daphnia parvula and Daphnia ambigua exposed to acute and chronic assay using copepods under laboratory conditions have been elaborated (Winner and Farrell 1976). Acute toxicity of an organophosphorus pesticide to Diaptomus fobesii has been reported (Mani and Konar 1984). Ceriodaphnia dubia and Daphnia magna have been used to evaluate the toxicity exerted by azulene and longigolene (Sweet and Meier 1997). Wastewater from paper and pulp mill has also been studied with respect to safe disposal rate (Ghosh and Konar 1980).

Studies on the toxicity of Cypermethrin to Daphnia magna has been reported (Ruparelia et al. 1995). A comparative toxicity of metal cadmium to copepods and Ostracods is reported (Onuoha et al. 1996). From the studies reported in literature it is evident that studies on freshwater zooplankton are limited to few specific types of chemicals and industrial wastewaters (Pablo et al. 1997; Dekruijj et al. 1988). No report on the herbal pharmaceutical wastewater toxicity on zooplankton is available with respect to zooplanktons. Main objective of this study was to evaluate the toxic effect of herbal pharmaceutical wastewater on major zooplankton species common to this region, since zooplankton are ecologically significant as fish food organisms in freshwater aquatic ecosystems. This article discusses in detail the toxicity evaluation of herbal wastewater to Ceriodaphnia dubia.

\section{Materials and Methods}

Zooplankton required for the toxicity evaluation studies were collected from a local freshwater lake. Freshwater containing mixed zooplankton population was first settled for one hour in glass beaker. With the help of fine Pasteur pipette the organisms were separated into a glass petri dish containing reservoir water and were observed for identification of species. The desired test species viz. Ceriodaphnia dubia was isolated for culture in isolation culture jar. Mass culturing of Ceriodaphnia dubia was carried out as per the methods described in literature (UNEP 1992). For the preparation of culture media dried cow dung $(5.0 \mathrm{~g})$ and garden soil $(25.0 \mathrm{~g})$ were mixed thoroughly with $1 \mathrm{~L}$ of filtered pond water and allowed to stand for 2 days then strained through a plankton cloth. The final culture medium was prepared by diluting 1 part of filtrate with 6-8 parts of de-chlorinated tap water. The filtrate was allowed to stand for 7 days and the settled sediment was discarded. The final culture medium was prepared by diluting one part of the filtrate with 6-8 parts of tap water. Ceriodaphnia dubia was cultured in $3 \mathrm{~L}$ wide mouth glass jar filled with two liters of the prepared culture media and 5-8 adults were introduced by a fine micropipette/Pasteur pipette. Within 8-10 days time, large number of Ceriodaphnia dubia species of uniform size was obtained for experimental purpose. Ceriodaphnia were fed with a culture of unicellular green alga Scenedesmus subspicatus. The food was provided to them twice a day at a concentration of 25,000 cells $/ \mathrm{mL}$. Then the organisms were separated from the culture flask and used for toxicity evaluation.

Wastewater required was collected from a local herbal pharmaceutical drug manufacturing unit. Wastewater was collected on hourly basis for $24 \mathrm{~h}$ and composited wastewater was used for the experiments. Combined wastewater thus prepared was subjected to neutralization as the raw wastewater was highly acidic with $\mathrm{pH}$ of 3.9-4.2. Combined raw wastewater, neutralized wastewater and physicochemically treated wastewater and biologically treated effluent were subjected to routine physico-chemical parameters as per the Standard Methods (1998) and the characteristics are shown in Table 1. Dilution water was prepared from the tap water by, passing it through an activated carbon column and aerated.

Physico-chemical characteristics of dilution water is indicated in Table 2. The BOD/COD ratio of the herbal pharmaceutical wastewater ranged between 0.51 to 0.60 indicating its high biodegradable nature. Subjecting this wastewater directly to biological treatment may not be cost effective, hence it was decided to treat the wastewater by physico-chemical method as a primary treatment. Reduction of the pollutants i.e. $69.40 \%$ BOD and $64.0 \%$ COD was achieved at the optimal dose of alum of $300 \mathrm{mg} / \mathrm{L}$ and $0.2 \mathrm{~mL} / \mathrm{L}$ of polyelectrolyte (Oxyflox-FL 11). This effluent depicted $25 \%$ reduction of toxicity. In spite of a $25 \%$ reduction in toxicity, the effluent was still toxic to the 
Table 1 Characteristics of herbal pharmaceutical wastewater
N.D. not detected

a All the values are expressed in $\mathrm{mg} / \mathrm{L}$. Except $\mathrm{pH}$ and colour

\begin{tabular}{|c|c|c|c|c|}
\hline Parameters $^{\mathrm{a}}$ & $\begin{array}{l}\text { Raw } \\
\text { wastewater }\end{array}$ & $\begin{array}{l}\text { Neutralized } \\
\text { wastewater }\end{array}$ & $\begin{array}{l}\text { Physico- } \\
\text { chemically } \\
\text { treated wastewater }\end{array}$ & $\begin{array}{l}\text { Biologically } \\
\text { treated effluen }\end{array}$ \\
\hline $\mathrm{pH}$ & $3.9-4.2$ & $6.8-7.4$ & $7.0-7.2$ & $7.0-7.8$ \\
\hline Colour & Dark yellow & Grey & Light yellow & Clear \\
\hline Total acidity/alkalinity & 1782 & 597 & 192 & 210 \\
\hline Total suspended solids & 1800 & 1602 & 294 & 46 \\
\hline Total solids & 4168 & 2532 & 536 & 98 \\
\hline Chemical oxygen demand (COD) & 12420 & 9200 & 3649 & 510 \\
\hline Bio-chemical oxygen demand (BOD) & 6890 & 4810 & 1660 & 160 \\
\hline Chloride as $\mathrm{Cl}$ & 160 & 136 & 80 & 40 \\
\hline Sulfide as $\mathrm{S}^{-}$ & 28 & 20 & 09 & 1.2 \\
\hline Sulphates as $\mathrm{SO}_{4}$ & 45 & 32 & 16 & 10 \\
\hline Phosphates as $\mathrm{PO}_{4}$ & 136 & 98 & 42 & 32 \\
\hline Total nitrogen as $\mathrm{N}$ & 224 & 132 & 68 & 38 \\
\hline Oil and grease & 82 & 36 & 12 & Nil \\
\hline Sodium as $\mathrm{Na}$ & 96 & 82 & 62 & 40 \\
\hline Potassium as $\mathrm{K}$ & 60 & 51 & 10 & 6 \\
\hline \multicolumn{5}{|l|}{ Heavy metals } \\
\hline Iron & 34.478 & 16.84 & 8.200 & 1.98 \\
\hline Copper & 0.5790 & 0.3120 & 0.2242 & 0.110 \\
\hline Manganese & 3.5462 & 1.1012 & 0.1692 & 0.102 \\
\hline Nickel & 0.8080 & 0.2364 & 0.1426 & 0.092 \\
\hline Zinc & 0.2742 & 0.1624 & 0.1000 & 0.060 \\
\hline Chromium & 0.2430 & 0.1204 & 0.1010 & 0.0646 \\
\hline Lead & 1.5623 & 0.9236 & 0.7214 & 0.078 \\
\hline Cadmium & 0.1010 & 0.0221 & 0.0923 & 0.041 \\
\hline Selenium & 0.2111 & 0.1321 & 0.0968 & 0.022 \\
\hline Arsenic & N.D. & N.D. & N.D. & N.D. \\
\hline
\end{tabular}

Table 2 Characteristics of dilution water

\begin{tabular}{lc}
\hline Parameters & Values $(\mathrm{mg} / \mathrm{L})$ \\
\hline Temperature $\left(0^{\circ} \mathrm{C}\right)$ & $25-27$ \\
$\mathrm{pH}$ & $7.9-8.2$ \\
Dissolved oxygen & $6.6-7.4$ \\
Total alkalinity as $\mathrm{CaCO}_{3}$ & $148-180$ \\
Total hardness as $\mathrm{CaCO}_{3}$ & $136-160$ \\
$\mathrm{Ca}$ hardness as $\mathrm{CaCO}_{3}$ & $60-78$ \\
$\mathrm{Mg}$ hardness as $\mathrm{CaCO}_{3}$ & $76-82$ \\
Calcium (as $\mathrm{Ca})$ & $24-31$ \\
Magnesium (as $\mathrm{Mg})$ & $20-24$ \\
Sodium (as Na) & $30-32$ \\
Potassium (as K) & $2-6$ \\
\hline
\end{tabular}

${ }^{a}$ All the values are expressed in $\mathrm{mg} / \mathrm{L}$. Except temperature and $\mathrm{pH}$

Ceriodaphnia. This treated effluent was further subjected to biological treatment by aerobic activated sludge system. Detailed studied were carried out at different mixed liquor suspended solids concentration (MLSS) which ranged between 2000 and $4000 \mathrm{mg} / \mathrm{L}$, Food to Microorganism
(F/M) ratio which ranged between 0.1 and 0.074 , hydraulic retention time (HRT) varying between 24 and $54 \mathrm{~h}$. Studies showed $4000 \mathrm{mg} / \mathrm{L}$ of MLSS, $0.18 \mathrm{~F} / \mathrm{M}$ ratio and an HRT of $42 \mathrm{~h}$ as optimum. This effluent showed good reductions in the heavy metal concentrations and oil content (Table 1). This treated effluent did not show any toxic effect on Ceriodaphnia dubia even after a prolonged exposure.

Bioassay experiments were carried out in $250 \mathrm{~mL}$ glass beakers with $100 \mathrm{~mL}$ test solution containing ten organisms in each beaker. The serial dilutions of wastewater were prepared as per requirement. The corresponding dilution water controls were also run. The toxicity tests were undertaken with three replicates each for control and experimental dilutions. Ten numbers of $48 \mathrm{~h}$ old newly hatched Ceriodaphnia dubia were randomly distributed to each of the test containers having different concentrations of wastewater ranging between $3 \%-6 \%$ for raw wastewater, $3.5 \%-12 \%$ for neutralized wastewater, and $20 \%-$ $30 \%$ for physico-chemically treated wastewater. The number of mortality in each container was observed at an 
interval of $12 \mathrm{~h}$ till $48 \mathrm{~h}$. Death was ascertained when the organisms failed to respond to very gentle prodding and did not exhibit any movement of the appendages. Dead organisms were removed using the pipette from the test beaker. The tests were carried out under constant temperature $\left(26^{\circ} \mathrm{C}+2^{\circ} \mathrm{C}\right)$ and light regime $(12 \mathrm{~h}$ photoperiod). Fortyeight hours acute static tests were performed for estimating the end points viz. No Observed Effect Concentration (NOEC), $\mathrm{LC}_{50}$ and slope function, $95 \%$ confidence interval and regression coefficient. Acute toxicity and median lethal concentration $\mathrm{LC}_{50}$ for $12,24,36$ and $48 \mathrm{~h}$ were determined as reported in literature (Sprague 1969; Finney 1971). 95\% confidence limit was also calculated as given in literature (Litchfield and Wilcoxin 1949).

\section{Results}

Freshwater zooplankton Ceriodaphnia dubia was exposed to raw, neutralized, physico-chemically treated and biologically treated herbal pharmaceutical effluent. Results obtained are indicated in Table 3 .

\section{Discussion}

Test organism Ceriodaphnia exhibited different degrees of susceptibility to the various wastewaters. However $\mathrm{LC}_{50}$ values still provide information for gross comparison of toxicity of the pollutants to the Ceriodaphnia. The studies revealed physico-chemically treated herbal pharmaceutical effluent to be comparatively less toxic while raw and neutralized wastewater depicted more or less same behavioral pattern. But neutralized wastewater was moderately less toxic than the raw wastewater. During the acute toxicity test, movements of Ceriodaphnia were restricted. Body of the Ceriodaphnia showed marginal reduction due to shrinkage caused by the effect of wastewater. Curling of antennae was also noticed. Eyes became dark and highly pronounced. From $\mathrm{LC}_{50}$ values it is clear that raw herbal wastewater exerts more toxicity.

Simple lime neutralization of the wastewater resulted in marginal reduction in COD, BOD and suspended solids. Hence there appeared to be a moderate improvement in the toxicity values. It is very clear that simple neutralization of wastewater is not suitable for discharge. This wastewater needs further treatment. So based on the results obtained with regard to raw and neutralized herbal pharmaceutical wastewater, the wastewater was further subjected to physicochemical treatment using conventional coagulants like lime, alum, ferrous sulphate and ferric chloride. Few polyelectrolyte additions to the above conventional coagulants were also tried. Combination of alum with cationic polymer (OxyfloxFL 11) (18) dose of 300:25 mg/L was found optimal. Effluent from this combination and dose was collected and subjected to toxicity evaluation. $\mathrm{LC}_{50}$ values indicated considerable reduction in toxicity by approximately $25 \%$.

Table 3 indicates $\mathrm{LC}_{50}$ values, slope function, confidence interval and regression values for 12, 24, 36 and $48 \mathrm{~h}$ time interval with respect to raw, neutralized and physicochemically treated wastewaters. Although physico-chemical treatment reduced the toxicity to a certain limit, it was

Table $3 \mathrm{LC}_{50}$, confidence limit, slope function and regression values for raw, neutralized and physico-chemically treated herbal pharmaceutical wastewater by Ceriodaphnia dubia

\begin{tabular}{ccccc}
\hline Sr. no. & Time $(\mathrm{h})$ & $\mathrm{LC}_{50}(\%)$ & $95 \%$ confidence interval & Slope \\
\hline Raw wastewater & & & & \\
1 & 12 & 4.5 & $4.01-5.04$ & $\mathrm{R}=16.942 \mathrm{x}-22.537$ \\
2 & 24 & 4.0 & $3.57-4.48$ & $\mathrm{Y}=21.768 \mathrm{x}-23.588$ \\
3 & 36 & $2.966-4.13$ & $\mathrm{Y}=22.05 \mathrm{x}-12.833$ \\
4 & 48 & 3.0 & $2.40-3.75$ & $\mathrm{Y}=21.685 \mathrm{x}-1.5548$ \\
Neutralized wastewater & & & \\
5 & 12 & 10.8 & $7.94-14.688$ & \\
6 & 24 & 4.0 & $4.86-10.08$ & $\mathrm{Y}=6.041 \mathrm{x}+5.4011$ \\
7 & 36 & $3.67-6.8$ & $\mathrm{Y}=6.5161 \mathrm{x}+22.068$ \\
8 & 48 & 3.9 & $\mathrm{Y}=0.0405 \mathrm{x}+4.612$ \\
Physico-chemically treated wastewater & & $\mathrm{Y}=7.1698 \mathrm{x}+32.0221$ \\
9 & 12 & 28 & $26.143-29.880$ & \\
10 & 24 & 26.6 & $24.186-27.950$ & $\mathrm{Y}=5.0874 \mathrm{x}-94.86$ \\
11 & 36 & 24.4 & $21.91-26.28$ & $\mathrm{Y}=5.4545 \mathrm{x}-95.455$ \\
12 & 48 & 22.16 & $\mathrm{Y}=5.7273 \mathrm{x}-92.182$ \\
\hline
\end{tabular}

$R^{2}$ regression 
still not suitable for discharge into the surface water bodies as the COD, BOD and SS values were more than the discharge standards and Ceriodaphnia did not survive for long duration. It is very clear from the studies that the wastewater needs further secondary treatment to comply with the standards. Therefore effluent from physico-chemical treatment was further subjected to biological treatment by aerobic activated sludge system. Characteristics of treated effluent are shown in Table 1. Ceriodaphnia thrived in this treated biologically treated effluent, indicating substantial removal of pollutants. Heavy Metals were found to be below the standard values. Moreover, emulsified oil was completely removed in this treatment. Detail studies indicate that the herbal pharmaceutical wastewater though highly biodegradable and herbal in nature is toxic to aquatic fauna. Hence the wastewater requires proper treatment before its discharge. Being herbal in nature this wastewater toxicity was never taken seriously. It is very evident from the results that herbal pharmaceutical wastewater is toxic to the fauna and needs complete treatment prior to its discharge. Toxicity evaluation studies would help the industry management to take necessary pollution control measures before effluent discharge into the natural streams. This would help in minimizing many eco-toxicological problems.

The studies indicated that the herbal pharmaceutical wastewater both raw and neutralized were highly toxic to Ceriodaphnia, While physico-chemical treatment reduced the toxicity by more than $25 \%$. It can be inferred from the studies that this herbal pharmaceutical wastewater needs further secondary treatment following physico-chemical treatment to reduce the toxicity. Ceriodaphnia an aquatic crustacean are very sensitive to toxic pollutants. They represent the indices of health and productivity of an aquatic ecosystem. Ceriodaphnia also constitute the base of aquatic food chain since most of the macro fauna thrive on plankton particularly zooplankton for their food. Zooplanktons represent the type of water body in which they thrive. Zooplankton organisms are significant link in aquatic food chain and play a major role in ecology as the aquatic population particularly fish thrive on them. Hence it is necessary to see that planktons grow luxuriously in water bodies.
Open Access This article is distributed under the terms of the Creative Commons Attribution Noncommercial License which permits any noncommercial use, distribution, and reproduction in any medium, provided the original author(s) and source are credited.

\section{References}

APHA (1998) Standard methods for examination of water and wastewater. APHA, AWWA, AWWA WPCF, Washington, DC

Dekruijj HAM, de Zwart D, Ray PK, Vishwanathan PN (1988) Manual of aquatic ecotoxicoloy. Allied Publishers Pvt. Ltd., New Delhi, p 332

Finney DJ (1971) Probability analysis, 3rd edn. Cambridge University Press, London, p 333

Ghosh TK, Konar SK (1980) Toxicity of chemicals and wastewaters of paper and pulp mills to worm, plankton and mollusks. Indian J Environ Health 22(4):278-285

Katalin VB (1995) Zooplankton for monitoring heavy metal pollution. In: Rana BC (ed) Pollution and biomonitoring. Tata McGraw Hills Publishing Co. Ltd., New Delhi, pp 302-324

Litchfield JT, Wilcoxin FA (1949) Simplified methods of evaluating dose effect experiments. J Pharmacol Exp Ther 96:99-113

Mani VGT, Konar SK (1984) Acute toxicity of Malathion to fish, plankton and worms. Environ Ecol 2(4):248-250

Onuoha GC, Nwadukwe FO, Erondu ES (1996) Comparative toxicity of cadmium to Crustacean zooplankton (Copepoda and Ostracoda). Environ Ecol 14(3):557-562

Pablo F, Buckney RT, Lim RP (1997) Toxicity of Cyanide, Iron cyanide complexes and a blast furnace effluent to the banana prawn Peanaeus monodon. Bull Environ Contam Toxicol 58:522-529

Ruparelia SG, Verma Y, Hargan MC, Venkaiah K, Kulkarni PK (1995) Toxicity of synthetic pyrethroid cypermethrin to Cichlid Sarotherodon mossambicus and Daphnis Daphnia magna. Indian J Environ Protect 15(6):415-419

Sprague JB (1969) Measurement of pollutant toxicity to fish: bioassay methods for acute toxicity. Water Res 4:3-32. doi:10.1016/00431354(70)90018-7

Sweet LI, Meier PG (1997) Lethal and sublethal effects of azulene and longifolene to microtox Ceriodapnia dubia, Daphnia magna and Pimephales promelas. Bull Environ Contam Toxicol 58:268-274. doi:10.1007/s001289900330

Tevlin MP, Burgis MJ (1979) In: Ravera O (ed) Zooplankton ecology and pollution studies in biological aspects of freshwater pollution. Pergamon Press, pp 19-38

UNEP (1992) Guidelines for assessment of ecological impacts on receiving water from discharges of paper and pulp mills Bangkok, Thailand, p 159

Vanerkar AP, Satyanarayan S, Dharmadhikari DM (2004) Toxicity of herbal pharmaceutical wastewater on fish Lebister reticulatuus (Peters). J Environ Sci Health B 39(1):115-123

Winner RW, Farrell MP (1976) Acute and chronic toxicity of copper to four species of Daphnia J Fish Res Board Can 33:1685-1691 